Reprod. Nutr. Dévelop., 1986, 26 (1 B), 337-338.

\title{
Digestibilité de régimes hyperlipidiques chez le poney
}

R. WOLTER, J. P. VALETTE

Laboratoire de Nutrition et Alimentation, Ecole Nationale Vétérinaire,

7, avenue du Général de Gaulle, 94704 Maisons-Alfort.

Summary. Six mature ponies were fed fat-supplemented diets in a latin square design to determine digestibilities. Fat addition to the diet did not modify organic matter or protein digestibilities, decreased cellulose and magnesium digestibilities but improved fat digestibility.

L'étude de la digestibilité des régimes hyperlipidiques chez les équidés s'inscrit dans le cadre des relations nutrition-aptitudes sportives. Elle conduit à la conception de régimes alimentaires spécialisés pour le cheval de sport. Bowman et al. (1977), Kane et al. (1979), ont montré que l'huile de maïs était bien acceptée par le cheval jusqu'à des taux de $20 \%$. Le but du présent travail est de tester sur des poneys des régimes enrichis en matières grasses d'origine animale et végétale.

Matériel et méthodes. Les mesures de digestibilité apparente par collecte totale des fécès pendant 5 jours sont conduites sur 6 poneys adultes selon un plan expérimental en carré latin (Valette, 1984) au cours de 2 essais (A et B) durant lesquels les animaux sont respectivement au repos et à l'entraînement. Les matières grasses sont extraites selon les normes AFNOR (1980) sans (procédé A) ou après hydrolyse (procédé $\mathrm{B}$ ) par $\mathrm{HCl} 3 \mathrm{~N}$.

Le régime témoin (T) est un aliment complet du commerce qui contient $3 \%$ de matières grasses, $14 \%$ de matières azotées, $18 \%$ de cellulose brute, $44 \%$ de parois (NDF) et $0,13 \%$ de magnésium. Les matières grasses ajoutées sont incorporées au moyen d'un mélangeur hélicoïdal à l'aliment témoin.

Dans l'essai $A$, les régimes expérimentaux renferment 10, 20 et $30 \%$ de saindoux. Dans l'essai $B$, les régimes expérimentaux contiennent $20 \%$ de saindoux (S) ou d'un mélange (SH) comportant pour moitié du saindoux et pour chaque autre quart de l'huile de tournesol et de la graisse de coprah. Les régimes $\mathrm{T}^{+}$et $\mathrm{SH}^{+}$ont été enrichis en magnésium $(+1,8 \mathrm{~g} / \mathrm{animal} / \mathrm{j})$ pour apporter $1,5 \mathrm{~g} / 100 \mathrm{~kg}$ poids vif/jour. Les quantités ingérées sont respectivement de $47 \mathrm{~g}$ $\mathrm{MS} / \mathrm{kg}$ PV 0,75 pour les régimes témoins et de $40 \mathrm{~g} \mathrm{MS} / \mathrm{kg} P V^{0,75}$ pour les régimes à $20 \%$ de matières grasses afin de fournir $155 \mathrm{kcal} \mathrm{d}^{\prime}$ énergie digestible par $\mathrm{kg}$ de poids métabolique.

Résultats et discussion. L'adjonction de matières grasses dans la ration du poney ne modifie pas la digestibilité des protéines, ni celle de la matière organique (tabl. 1 et 2). Elle améliore la digestibilité des matières grasses par une diminution du rapport endogène/ingéré. Les lipides excrétés, avec l'aliment témoin, étaient en grande partie d'origine endogène. La digestibilité des lipides à forte teneur en acides gras saturés est élevée (près de $90 \%$ ) mais elle apparaît plus faible que celles 
des lipides riches en acides gras insaturés (huile de tournesol) ou à courtes chaînes (graisse de coprah) que l'on peut estimer d'après nos calculs à presque $100 \%$.

TABL. 1. - Digestibilité apparente des régimes (\%) de l'essai A.

\begin{tabular}{|c|c|c|c|c|c|c|c|}
\hline \multirow{3}{*}{$\begin{array}{l}\text { Taux de saindoux } \\
\text { Matière organique }\end{array}$} & \multicolumn{2}{|r|}{0} & \multicolumn{2}{|c|}{10} & \multicolumn{2}{|c|}{20} & 30 \\
\hline & 70,2 & 2,0 & $68,9 \pm$ & 2,7 & $68,0 \pm$ & 2,2 & $65,1 \pm$ \\
\hline & 76,4 & 2,0 & $74,5 \pm$ & 2,8 & $74,6 \pm$ & 3,9 & $74,5 \pm 9,3$ \\
\hline Matières grasses (procédé A) & 34,1 & $\pm 20,9 a$ & $71,7 \pm$ & $9,7 \mathrm{~b}$ & $83,5 \pm$ & $\pm 10,4 \mathrm{~b}$ & $85,6 \pm 12,2 b$ \\
\hline Matières grasses (procédé B) & 51,4 & $\pm \quad 7,8 \mathrm{a}$ & $62,6 \pm$ & $10,0 \mathrm{~b}$ & $83,1 \pm$ & $\pm 10,2 \mathrm{c}$ & $81,3 \pm 12,8 c$ \\
\hline Cellulose brute & 50,2 & $3,6 a$ & $48,3 \pm$ & $6,8 a$ & $41,8 \pm$ & $\pm 5,4 \mathrm{~b}$ & $36,4 \pm 9,6 c$ \\
\hline Parois totales (NDF) & 58,1 & $4,6 a$ & $56,1 \pm$ & $3,8 \mathrm{a}$ & $50,2 \pm$ & $7,1 b$ & $46,5 \pm 10,1 \mathrm{~b}$ \\
\hline
\end{tabular}

TABL. 2. -- Digestibilité apparente des régimes (\%) de l'essai $B$.

\begin{tabular}{|c|c|c|c|c|c|c|c|c|}
\hline Régime & & $\mathrm{T}$ & & $\mathrm{T}^{+}$ & $\mathrm{SH}$ & $\mathrm{SH}$ & & s \\
\hline Matière organique & 69,7 & 3,2 & 68,5 & 2,8 & $68,4 \pm$ & $66,9 \pm$ & 4,5 & $62,7 \pm$ \\
\hline $\begin{array}{l}\text { Azote } \\
\text { Matières qrasses }\end{array}$ & 72,1 & $\pm \quad 4,6$ & 72,3 & $\pm 3,9$ & $73,9 \pm 3,9$ & $75,1 \pm$ & 5,8 & $71,9 \pm 9,3$ \\
\hline $\begin{array}{l}\text { (procédé A) } \\
\text { Matières grasses }\end{array}$ & 40,4 & $\pm 14,4 a$ & 36,1 & $\pm 11,6 \mathrm{a}$ & $81,9 \pm 4,3 b$ & $79,9 \pm$ & $5,3 b$ & $75,6 \pm 9,9 b$ \\
\hline (procédé B) & 62,2 & $\pm 8,7 a$ & 59,0 & $\pm 7,4 a$ & $83,1 \pm 4,1 b$ & $81,2 \pm$ & $4,9 \mathrm{~b}$ & $77,1 \pm$ \\
\hline $\begin{array}{l}\text { Cellulose brute } \\
\text { Parois totales }\end{array}$ & 55,7 & $\pm 5,8 \mathrm{a}$ & 53,3 & $\pm 3,9 a$ & $47,7 \pm 8,4 a b$ & $46,0 \pm$ & $8,1 b$ & $41,5 \pm$ \\
\hline $\begin{array}{c}\text { (NDF) } \\
\text { Magnésium }\end{array}$ & $\begin{array}{l}56,7 \\
14,0\end{array}$ & $\begin{array}{l} \pm \quad 4,9 a \\
\pm 13,5 a\end{array}$ & $\begin{array}{l}55,5 \\
31,8\end{array}$ & $\begin{array}{l} \pm \quad 2,8 a \\
\pm 15,5 b\end{array}$ & $\begin{array}{l}49,1 \pm 5,8 b \\
21,4 \pm 14,9 a\end{array}$ & $\begin{array}{l}49,9 \pm \\
31,8 \pm\end{array}$ & $\begin{array}{r}6,3 \mathrm{~b} \\
14,5 \mathrm{~b}\end{array}$ & $\begin{array}{r}44,7 \pm 8,8 \mathrm{~b} \\
0,6 \pm 20,0 \mathrm{c}\end{array}$ \\
\hline
\end{tabular}

a-B, b-c, ou a-c indiquent des moyennes significativement différentes au seuil 0,05 .

Cette incorporation de matières grasses détériore la digestibilité de la cellulose et des parois, soit en raison d'une accélération du transit, soit d'une inhibition de la cellulolyse caeco-colique par les lipides non digérés. Elle diminue aussi l'absorption du magnésium, dans le cas du saindoux, sans doute par formation de savon (Rayssiguier, 1981).

Les fluctuations individuelles observées avec le régime 30 sembleraient indiquer les limites d'adaptation de l'organisme des animaux aux taux importants de matières grasses. Quant à celles observées avec le régime $S$ en période d'entraînement, elles traduiraient la légère infériorité du saindoux par rapport au mélange d'huile de tournesol et de graisse de coprah, infériorité que l'on retrouve exprimée dans les digestibilités de la cellulose, des graisses et du magnésium (différence significative seulement pour $\mathrm{Mg}$ ).

AFNOR, 1980. Détermination de l'extrait à l'éther diéthylique NVF 18104, Juin.

Bowman V. A., Fontenot J. P., Webb K. E., Meacham T. N., 1977. Digestion of fat by the equine. Livest. Res. Rep., 172, 72.

Kane E., Baker J. P., Bull L. S., 1979. Utilisation of corn oil supplemented diet by the pony. J. anim. Sci. 48, 1379-1384.

Rayssiguier Y., 1981. Magnesium and lipids interrelationships in the pathogenesis of vascular diseass. Magnesium Bull., 1a, 165-177.

Valette J.P., 1984. Nutrition lipidique et aptitudes à l'effort d'endurance chez le poney. Th. Doct., Nutr., Univ. Paris VI. 